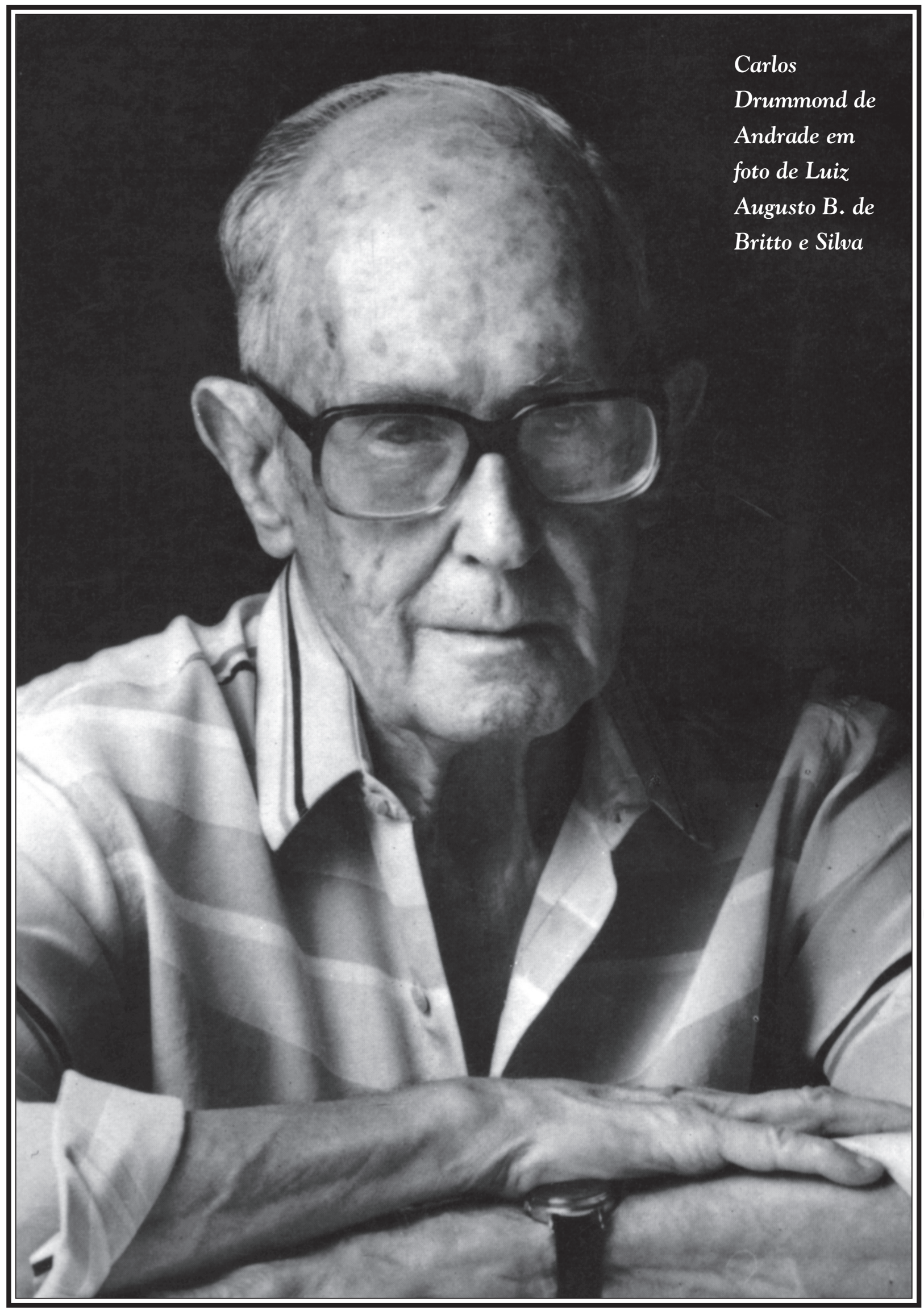




\section{A visita dos afetos}

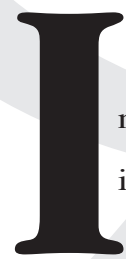

nverno ou verão, raras são as visitas na cidade grande. Só o impulso dos afetos leva ao encontro, no labirinto dos compromissos urbanos, profissionais, familiares. A casa de José Mindlin lá está à espera da visita: apesar do movimento cosmopolita, há sempre uma atenção acolhedora dos que atendem à porta aos visitantes de várias partes do mundo que estão de passagem ou aos amigos da terra. Chega-se ao abraço da Guita, que logo se prontifica para chamar o José na biblioteca. Onde estaria ele, às 9 horas de uma manhã de maio, senão no refúgio dos livros? Em poucos minutos aparece, atravessando o jardim que separa o prédio do acervo à casa principal. Sobe os degraus com agilidade; aproxima-se sorridente da sala de visitas e de imediato se torna cúmplice de um texto em memória e paixão pelo centenário de Carlos Drummond de Andrade.

Prefere a mesa de jantar para o trabalho. Aí se espalham livros, recortes de jornal, em seguida chegarão as cartas do poeta, as dedicatórias. As mãos querem tocar no livro e, inquieto, busca os

CREMILDA MEDINA

é jornalista, professora da Escola de Comunicações e Artes da USP e coordenadora da CCS-USP. 
óculos, que já estavam ali antes de chegar à sala, para ler o que escreveu sobre o Drummond, não lembra mais com precisão, na página 94 de Uma Vida entre Livros, Reencontros como Tempo. (Essa edição, lançada pela Edusp/Companhia da Letras em 1997, ainda o emociona.) Nota-se o natural cansaço da visão, apesar do vigor dos 87 anos. Mindlin brinca com a contingência - os olhos não dão mais conta da fome de leitura. Lembra então a história do condenado à prisão perpétua que recebe o velho amigo na cadeia e comenta com misericórdia, meu Deus, você preso aqui a vida inteira... Não, companheiro, só de hoje em diante.

Afetuosamente, aceita que lhe leia os textos e ouve com atenção as páginas de sua autoria em que narra o laço que se amarrou entre ele e Drummond. Ainda que tenha sido tardio, já nos anos 70, o convívio foi cada vez mais reforçando uma amizade madura, daquelas que conjugam o diálogo cotidiano e o respeito ao mistério de cada um. O poeta sabia modular este percurso entre a superficialidade dos encontros e a entrega de confiança aos amigos assinava Carlos Drummond de Andrade no comum da correspondência e passava a assinar Drummond quando alguém conquistava seu afeto. Foi assim com José Mindlin. Nosso relacionamento foi uma das boas coisas que me aconteceram na vida, escreve, e se delicia agora com a verdade que registrou no livro. Lembro-me de ter dito, numa das homenagens que lhe foram prestadas quando completou oitenta anos, cercado de velhos amigos, como Pedro Nava, Afonso Arinos, Abgar Renault, Cyro dos Anjos, e muitos outros, que eu me sentia como quem chegou a um banquete já na hora da sobremesa ... Mas assim mesmo valeu a pena. Creio poder dizer que fomos muito amigos, mesmo não sendo íntimos. (Pede licença delicadamente para interromper a leitura e observa, com ar grave: essa intimidade total aconteceu na visita que fez a Drummond, logo depois da perda de Maria Julieta, a filha amada. José Mindlin estava fora do Brasil uns dias antes quando ela morreu e, tão logo voltou, correu para o Rio, queria estar junto dele na dor. Ficaram conversando horas a fio, mergulharam nos abismos da alma humana, selaram o pacto definitivo das confissões. Em seguida, Drummond foi para o hospital, deixou este mundo no dia 17 de agosto de 1987 , ficou para a eternidade a sua poesia.)

Na pré-história da amizade, há vestígios que surpreendem o próprio Mindlin, quando se sai da mesa de jantar para a mesa da biblioteca e Elisa Nazarian, a mestre de cerimônia desse espaço sagrado, autora de um projeto de biblioteconomia também espantoso Mindlin faz questão de a enaltecer com largos gestos de reconhecimento -, pois bem, Elisa traz as pastas, testemunho histórico do elo entre o poeta e o bibliófilo. Ali está a primeira correspondência de 1937. Não se lembrava do remoto registro, tinha quase certeza de que o começo remontava aos anos 70. Que seria? Os olhos brilham com a curiosidade de uma criança: vamos ver o que é isso, não tenho a mínima lembrança desse episódio. Lê-se que o envelope vem timbrado do Ministério de Educação e da chefia de gabinete. Drummond, chefe de gabinete do então ministro Gustavo Capanema, agradece o oferecimento de dois volumes do trabalho O Destino de uma Herança, de autoria do advogado Antônio Augusto Covelo. Mindlin logo observa: é verdade, trabalhava com ele nos seus tempos de advocacia.

O segundo momento vem em 1975. Mindlin, já como empresário, patrocinou, pela Metal Leve, a reedição de A Revista. Começa então um ciclo de correspondência que vem até à morte de Drummond. Depois de uma troca de cartas cerimoniosa em que se tratavam com todas as doutorias de praxe, o poeta escreveu, no primeiro exemplar, uns versos que deleitaram o editor:

\author{
A Revista dormia em seu jazigo pobre, \\ eis chega José Mindlin, e vara de condão em punho \\ ressuscita-a e para nós descobre \\ em seu rosto fanado imprevisto clarão.
}


A nova etapa de convívio vai ter como cenário a biblioteca de Plínio Doyle, no Rio de Janeiro. Outro consagrado bibliófilo como José Mindlin, recebia visitas dos intelectuais que, como ele, reverenciavam o livro. Nos famosos sabadoyles, registrados em atas, Mindlin começou a encontrar Drummond com regularidade. Mas, nesses inesquecíveis sábados, prevalecia o culto ao poeta-mito, Mindlin avalia agora com a perspectiva do tempo: eu olhava pra ele de baixo para cima, era pra mim uma figura superior. A grande inflexão da pré-história para a história da sólida amizade será marcada, ainda uma vez, pela metáfora da visita. Foi num dos sabadoyles que eu disse ao Drummond que queria fazer uma edição de arte de um texto dele, mas que fosse inédito, e ele respondeu: “Olha, obrigado pela idéia, só que, de imediato, não tenho nada expressivo. Mas estou trabalhando em um poema sobre um episódio que me impressionou a vida inteira. Se conseguir terminar, mando para o senhor". Não precisa do prosseguimento da leitura, tem na ponta da língua a resposta do poeta três meses depois: promessa cumprida. Aí vai o texto. A visita de Mário de Andrade a Alphonsus de Guimaraens, em 1919, numa metamorfose poética de Drummond, selaria o encontro pleno de dois amigos.

Drummond e Mindlin negociaram seis meses para que o poema se tornasse um livro de arte em 1977. Faz-se uma pausa para saborear detalhes das cartas trocadas. Imaginese o poeta, engajado até mesmo na escolha da família tipográfica. Depois de estudos recorrentes, a decisão, prefiro o Bodoni. Mindlin, sempre cercado de amantes do livro seja na expressão lingüística seja na expressão visual ou no próprio objeto de arte, teve dores de cabeça consideráveis com essa etapa da relação. Isso porque Drummond participou de todos os passos da edição. A ilustração (por exemplo) deu trabalho: ele pensou em desenhos de um jovem artista do Rio, que não cheguei a ver, porque não queria correr o risco de não gostar e criar uma situação constrangedora. Barroco não tinha nada a ver com o texto, e eu tinha pensado em fotos antigas, ou uma fotografia onírica. Che gamos a convidar Renina Katz, mas ela, embora gostando muito da idéia de ilustrar um livro de Drummond, achou que seu trabalho não combinava em absoluto como texto. Escreveu ao Drummond explicando isso, e me mostrou a carta, que teve uma conseqüencia engraçada. Nessa carta, ela tratava o Drummond de "você", e eu, vendo isso, propus a ele que nós também eleminássemos o tratamento cerimonioso, o que ele aceitou prontamente. Mas voltemos à ilustração. Guita e eu convidamos então a grande fotógrafa Maureen Bisilliat, muito nossa amiga, para ir conosco a Ouro Preto e Mariana, em busca de inspiração. E foi lá que Maureen apanhou umas pedrinhas na rua, e disse: "Afinal, a pedra é a essência de Minas. Por que nãofazemos macrofotografias destas pedras?" Fez. a experiência, que deu certo, e a solução foi adotada. Só a capa e uma ilustração (repetição da capa) foram figurativas - a cabeça de mulher em mármore, dando a possível idéia de beleza feminina de Alphonsus de Guimaraens. Mas as outras, mesmo abstratas, combinaram surpreendentemente bem com o texto.

Os arquivos guardam revelações e deslumbramentos. Nessa visita a José Mindlin, maio de 2002, para celebrar o centenário de Drummond. Descobre-se que o editor e o poeta chegaram a negociar a arte poética. Versos de linha larga não se adequavam à diagramação. Pode-se conceber hoje tal conflito? O autor reagiu, engoliu em seco a irritação. Que atrevimento. Mindlin argumentava, o livro vai ser oblongo. Drummond de pronto, não gosto. Mindlin, pacientemente, veja, a linha longa do verso não cabe, é preciso quebrar. Drummond, teimoso, não gosto de quebrar linha. Lá está nas pastas da biblioteca, a carta de 14 de setembro de 1977 que atesta a humilde serenidade do criador, após ter digerido o incômodo: 
Meu caro Mindlin,

Bom dia.

Depois de meditar sobre o probleminha gráfico, resolvi cindir em dois aquele verso quilométrico da parte III de "A Visita". Ficou assim:

(Menti para ele, Deus!

E a minha Gota de Sangue em Cada Poema?)

Você notará que retirei o possessivo de exclamação a Deus. Acho que o Mário gostaria de abrir mão da propriedade exclusiva de Deus, para devolvê-la à universalidade. E como cortar palavras ainda é a maneira de escrever, cassei o $\underline{\text { meu. }}$.

Na parte VI, fiz igualmente uma pequena modificação. Onde estava com demasia de verbos e lerdeza de tempo:

Vai começar a nascer outra visita,

Acelerei para:

Começa a nascer outra visita,

Outra coisa. A nota final, explicativa da minha liberdade em utilizar versos alheios, continha uma impropriedade. O livro "Itinerário" não é de autoria de Alphonsus de Guimaraens, que o organizou basicamente com as cartas recebidas de Mário e Bandeira, enriquecendo do texto com introdução e notas, estas, sim, de sua autoria. Então, a minha nota fica mais correta nestes termos:

No corpo deste poema,

foram utilizados

versos, fragmentos de versos

e informações

encontráveis nos livros

Obra Completa,

De Alphonsus de Guimaraens;

Poesias Completas,

De Mário de Andrade,

$\mathrm{e}$

Itinerários -

- Cartas a Alphonsus de Guimaraens Filho.

E é só, desta vez, com meu agradecimento renovado pelo seu zelo, perícia e carinho postos na execução do projeto. $\mathrm{O}$ abraço amigo do seu Carlos Drummond de Andrade P.S. Gostaria de ver as provas finais, de página. É possível? CAD 
A visita de Mário de Andrade a Alphonsus de Guimaraens em 1919, por algum motivo misterioso, fez Drummond sair de seu apartamento na Rua Conselheiro Lafayette para a viagem poética. A Visita, nas mãos de José Mindlin, sua filha Diana, Maureen Bisilliat, Antônio Marcos da Silva, saiu com arte e esmero em 125 exemplares que logo se esgotaram. No natal de 1979, o Banco de Boston patrocinou uma edição fac-similar, hoje também esgotada. O poema faz parte de outra obra A Paixão Medida, mas o condão das visitas espalha magia - em 1996, a italiana Luciana Stegagno Picchio preparou uma edição, com sua introdução e uma revisitação aos três poetas. A Visita segundo Alphonsus, a Visita segundo Mário de Andrade, a Visita a Drummond segundo José Mindlin e $A$ Visita (Milão, Libri Scheiwiller). Também dos inúmeros encadernadores que fazem a peregrinação à casa do Brooklin, há vestígios dos que não resistem ao encantamento do volume original. Assim aconteceu com a encadernadora francesa Godelive de Saint Cyr que revestiu A Visita com seu toque artístico. A dedicatória de Drummond assinala, a 17 de dezembro de 1977, a inflexão definitiva da amizade:

\section{A José E. Mindlin}

que, com sensibilidade artística de esteta e devoção à poesia, idealizou, projetou e executou o corpo gráfico - perfeito - deste livro.

O abraço agradecido, contente e afetuoso

Carlos Drummond de Andrade

No acervo de Mindlin sucedem-se então dedicatórias, cartas e tantas outras marcas de afeto que dariam muitos metatextos. Ele se perde e se acha na memória viva que está ali na biblioteca ou nos demais espaços da casa. A vontade que tem é mexer e mexer nas prateleiras e não sabe se vai aos poemas ou às cartas. Ó, maravilha, A Paixão Medida. Veja, a dedicatória.

Com afetuoso abraço ao meu amigo José Mindlin:

Uma paixão só pode ser medida

pelo fogo que a envolve, pelo gozo

que despetala sobre a nossa vida

e pelo fim, amargo e silencioso.

Carlos Drummond de Andrade

Rio, 28.VI.1981

Um ano antes, mais precisamente abril de 1980, o primeiro livro publicado de Drummond completava meio século. Conversei com José Mindlin, no fim de 79, em uma exposição no Masp, a respeito da data de aniversário de Alguma Poesia. Comentamos sua negativa radical a entrevistas (na época, editora de artes e cultura de O Estado de S. Paulo, eu não podia deixar passar a oportunidade. Precisava visitar o poeta). Mindlin ficou excitado com a missão impossível - o silêncio de Drummond era barreira intransponível para jornalistas. Mas me prometeu intervir. Até hoje desconheço quais os argumentos que levaram o poeta a marcar o encontro. O fato é que no último sábado de março estava na sala de visitas, num estado de tensão que só iria aliviar na terça-feira de manhã cedo, 1ㅇ de abril de 1980, quando abri o jornal e lá estava a página impressa - Cinqüenta anos de poesia brasileira nas veias de Drummond. (Os telegramas que chegaram naquele dia marcaram para sempre esse trabalho, mas nada se compara ao cartão do poeta que chegou logo em seguida à publicação.) 


$$
\begin{aligned}
& \text { Rio, } 5 \text { de abril. } 1980 . \\
& \text { Cara Gemilda: } \\
& \text { Agros sei papue cocè nầ puiv higan o harader. } \\
& \text { cora pui, te a tua mocuória excepcimal } 1 \text { a sua accidace } \\
& \text { inuabitica valem mair d pre essa enfenhoca moduna? } \\
& \text { Fivei adcuirad in a rapidey da feitira bitexh. } \\
& \text { E encantad cun a dimpatia, a banne face da entre- } \\
& \text { vistadora, avilmg de um dialoge gue neue una veg me pa- } \\
& \text { recen impartuno on tendenciso: pelo centainis. } \\
& \text { Otrigad, amisa! pahed pue a tua presousa } \\
& \text { un uma carc beve de bnu. bolwes a a adece as } \\
& \text { livdar fence as lindar palarras. } \\
& \text { cariuhnamente, oceluaso ds velles }
\end{aligned}
$$

Carta de

Drummond

a Cremilda

Medina

$$
\text { Drumumd }
$$

Naquele sábado, saímos cedinho de Congonhas, Mindlin, Diana e eu. A ponte aérea e o táxi para Copacabana demoraram uma eternidade, devíamos chegar às 10 horas na casa do poeta. Receber de manhã já era uma violentação do turno sagrado da escrita (conhecia esse hábito e Mindlin o reafirmara: o trabalho, para Drummond, era matutino e ele se fechava para o mundo no escritorinho do apartamento). De repente, lá estávamos na sala de visitas, 10 horas em ponto, Dolores, a esposa, absoluta discrição, Drummond, receptivo com a estranha, familiar com os amigos Mindlin e Diana. Como trabalhar nesse clima de cotidiano: uma visita de fala à toa, o tempo (calor danado de Rio de Janeiro), a viagem (não havia muito o que render, ponte aérea sem teto fechado em São Paulo, vôo normal...), a disposição à vontade no sofá e nas cadeiras da sala de estar, Drummond, com delicadeza, acomodou Mindlin e Diana junto a Dolores à direita na sala e me puxou para a esquerda, cadeiras lado a lado. Ele próprio deu o sinal que estava ali para me atender, afinal o que vinha fazer? (Entrevista, não faço, é contra os meus princípios...) Levava um gravador na bolsa, se por acaso o poeta o exigisse. Perguntei como quem não espera resposta positiva: queria gravar a nossa conversa, fazia questão? Disse que não, tinha certa ojeriza à maquininha. Gancho perfeito: eu quase nunca trabalho com essa muleta. Começa, para valer, a visita a Carlos Drummond de Andrade. 
Manifestei meu desejo de não estar invadindo a privacidade. Ele logo atalhou, corre por aí esse mito de que sou arredio, não dou entrevistas, fujo de solenidades e vida social. É verdade que não gosto disso... Qual seria o motivo? Talvez.porque fui durante muito tempo funcionário público e era obrigado, por compromissos profissionais, a ter constante contato com muita gente. E como era terceiro escalão, sabe como é, as pessoas vêm sempre ou pedir alguma coisa ou criar uma situação para pedir alguma coisa logo em seguida. Quase sempre nem sabem muito bem o que estão pedindo, nem é nada importante, porque, se não, iriam pedir a alguém com poder de decisão, não a um funcionário de terceiro escalão, um oficial de gabinete. Depois, ainda precisava representar o gabinete em certas solenidades, onde nunca me sentia à vontade. Foi aí que peguei essa aversão a locais públicos. Mas gosto muito de conversar, principalmente com gente jovem, que tem alguma coisa nova a dizer. Os velhos, encontro sempre e já sei o que vão falar...

Timidez, respostas esquivas, a fama de que fugia do olho no olho caem por terra nos primeiros minutos da visita. Um Drummond bem-humorado, ginasta das palavras, ainda que as articulasse com economia oral de sílabas, movia os olhos azuis como um radar pela sala, sempre pronto para uma tirada, uma delicada ironia. Seria o humor do ancestral clã medieval dos Drummond? (Mindlin conta em seu livro que quis averiguar a origem, quando descobriu o parentesco em Earl of Perth, mas Drummond rejeitou a pesquisa genealógica, preferiu chegar até os avós, já que já tinha descoberto os do clã do Bem e os do clã do Mal. Ao que tudo indica, ele vinha dos maus...) A rigor, logo à partida na sua poesia se pronunciou:

\author{
Quando nasci, um anjo torto \\ desses que vivem na sombra \\ disse: Vai, Carlos! ser gauche na vida.
}

Afinal, a visita aos 77 anos estava regida pelos 50 da poética inaugural. A conversa teria esse rumo, justamente porque voltar ao primeiro livro de Drummond era pressentir o grande itinerário que o Brasil e o mundo conhecem. Uma primeira questão intrigante - por que o título Alguma Poesia? Se não lembrasse, passadas cinco décadas, não tinha importância. Se faz tanta pergunta besta. Mas Drummond não negou fogo: Um título maroto. Usei da ambigüidade desse alguma. Tanto pode ser a modéstia, alguma entre muitas. Ou orgulho, uma certa poesia. De saída o título do livro foi motivo de críticas e chegou a ponto de Medeiros de Albuquerque dizer que melhor seria se intitulasse “Nenhuma poesia em alguma tipografia". No dia 25 de abril de 1930, o primeiro livro de Drummond impresso pelo escritor Eduardo Frieiro nas oficinas do Minas Gerais (órgão oficial do Estado) marcava uma poesia ímpar e incompreendida à época. Não faz mal, pagou a edição do seu bolso, com descontos em folha de pagamentos do jornal, e que saiu sob a marca editorial fictícia Edições Pindorama.

A consciência da ousadia e dos riscos a guardou na memória e, naquela manhã de sábado em Copacabana, brincou com o legado do anjo torto: Esse primeiro poema, por exemplo, não obedeceu a nenhum projeto. É o que se pode chamar poema-colagem. Tinha vários versos soltos e decidi juntar em um poema. Por que enveredei, de imediato, por um caminho antiacadêmico, usando palavras mais concretas, usando de humor? Você me pergunta isso, mas não tenho resposta clara, porque não se tratava de opção, mas de meu jeito de ser. Lembro até uma frase que uma faxineira disse para outra empregada da casa, que era meio metida a certas erudições: "Tu é o que tu é". Eu sou o que eu sou, sou mineiro, e mineiro é, em geral, reticente, oblíquo. Considero Machado o maior escritor brasileiro e dele extraio a lição de não fazer o discurso direto iluminado por todos os lados. Acho que partilho de certa prevenção contra as verdades absolutas. 
Lembro aí também de uma história do Fernando Sabino: um sujeito, mineiro é claro, vendia café e chegou um comprador que lhe fez a pergunta frontal - seu café é bom?ao que respondeu, olha, nunca ninguém se queixou. Meu apego às coisas concretas, aos fatos simples da vida, talvez venha também de meu pai que era fazendeiro e me ensinou a encarar a vida frente a frente, ir direto ao fato. Uns acham, eu sei, que isso é apelar para a vulgaridade, a banalidade. Houve até campanhas contra a minha poesia, chamando-a de apoética. Acontece que nessa época, antes da formação dos cursos de Letras no Brasil, os "críticos" eram professores de português, promotores e outros bacharéis que só conheciam Eça de Queiroz, José de Alencar, Machado (mal lido) e Olavo Bilac - desconheciam também os poemas diferentes de Bilac, em que concordava poeticamente singular com plural...

No calor do fim da manhã, início da tarde, Drummond aumentava o ritmo das histórias, das tiradas de humor. Chegava mesmo a dar a mão à palmatória - seria o santo (o clã do Mal) dos escoceses que lhe estava grudado à pele. E os críticos das outras tribos queriam depreciar essa força. Diziam que atrofiava o lirismo: É, já disseram que olirismo em mim está sufocado pelo humour, que, para mim, é uma visão profunda da vida. Então como esse traço é mais acentuado em mim, é natural que o lirismo fique um pouco sufocado. Mas há nos meus versos muitas contradições, o homem não é um ser uno. Assim como um religioso pode virar mundano, um comunista pode entrar num convento. Acho que o poeta deve partir de uma base concreta de realidade, mas já escrevi também que não se façam versos sobre acontecimentos.

De qualquer maneira, com ou sem querelas críticas, Carlos Drummond de Andrade - do primeiro ao último livro - será eternamente associado à poesia do cotidiano.

\author{
Casas entre bananeiras \\ mulheres entre laranjeiras \\ pomar amor cantar. \\ Um homem vai devagar. \\ Um cachorro vai devagar. \\ Um burro vai devagar. \\ Devagar... as janelas olham. \\ Eta vida besta, meu Deus.
}

Na sábia serenidade dos 77 anos, ele avaliava que a poesia brasileira, nos anos 30, quando ergueu suas fundações, andava de paletó e gravata, sonhava com reminiscências gregas, apesar do espírito nacionalista, estava intoxicada de cultura francesa. Drummond lembrou Mário de Andrade, que redescobriu o Brasil e ele, o seu cantinho. Custei a sentir o Brasil como alguma coisa ligada a meu sangue. Acho que em Alguma Poesia ainda não estava totalmente desintoxicado do vírus da cultura francesa. Quando a tarde já começa a esquentar na sala de visitas, naquele sábado de 1980, o arguto observador do mundo e do Brasil se desloca, com facilidade, para os assuntos políticos, assuntos metafísicos e existenciais. Incrível que aparecem, emergentes, no primeiro livro e a troca de impressões entre a leitora e o poeta serve de guia para espantos, reticências, perguntas que levam a afundamentos e lá ficam nos silêncios do diálogo respeitoso. Drummond, no entanto, não cansa perante os desafios, sobretudo no que tange à criação. Sua poesia é porque é, mas pensa na criação em voz alta perante a visita ali instalada há mais de três horas: Uma das dificuldades do verso livre é que não se sabe quando acaba. O poemaé arbitrário na sua composição, é difícil fazê-lo em um tempo determinado. Mas para além das dúvidas, expressa uma noção clara da criação artística: Um compromisso entre a razão e a loucura, entre a razão e o sonho. 
Hoje, José Mindlin, com dez anos a mais do que o Drummond de nossa visita em 1980, prefere guardar as lembranças do amigo nos seus momentos de sonho e de loucura. A conversa no Brooklin Paulista já está acabando e nos debruçamos ainda uma vez na obra dileta do bibliófilo, A Paixão Medida. Nesse título, a síntese poética do que falara Drummond, razão e loucura, ou melhor, a loucura temperada pela razão. Não sei. Olho o belo exemplar das Edições Alumbramento (1980) e recorro à voz desse centenário Senhor da Poesia Brasileira:

Já não quero dicionários consultados em vão.

Quero só a palavra

que nunca estará neles

nem se pode inventar.

Que resumiria o mundo

E o substituiria.

Mais sol do que o sol,

dentro da qual vivêssemos

todos em comunhão,

mudos,

saborando-a.

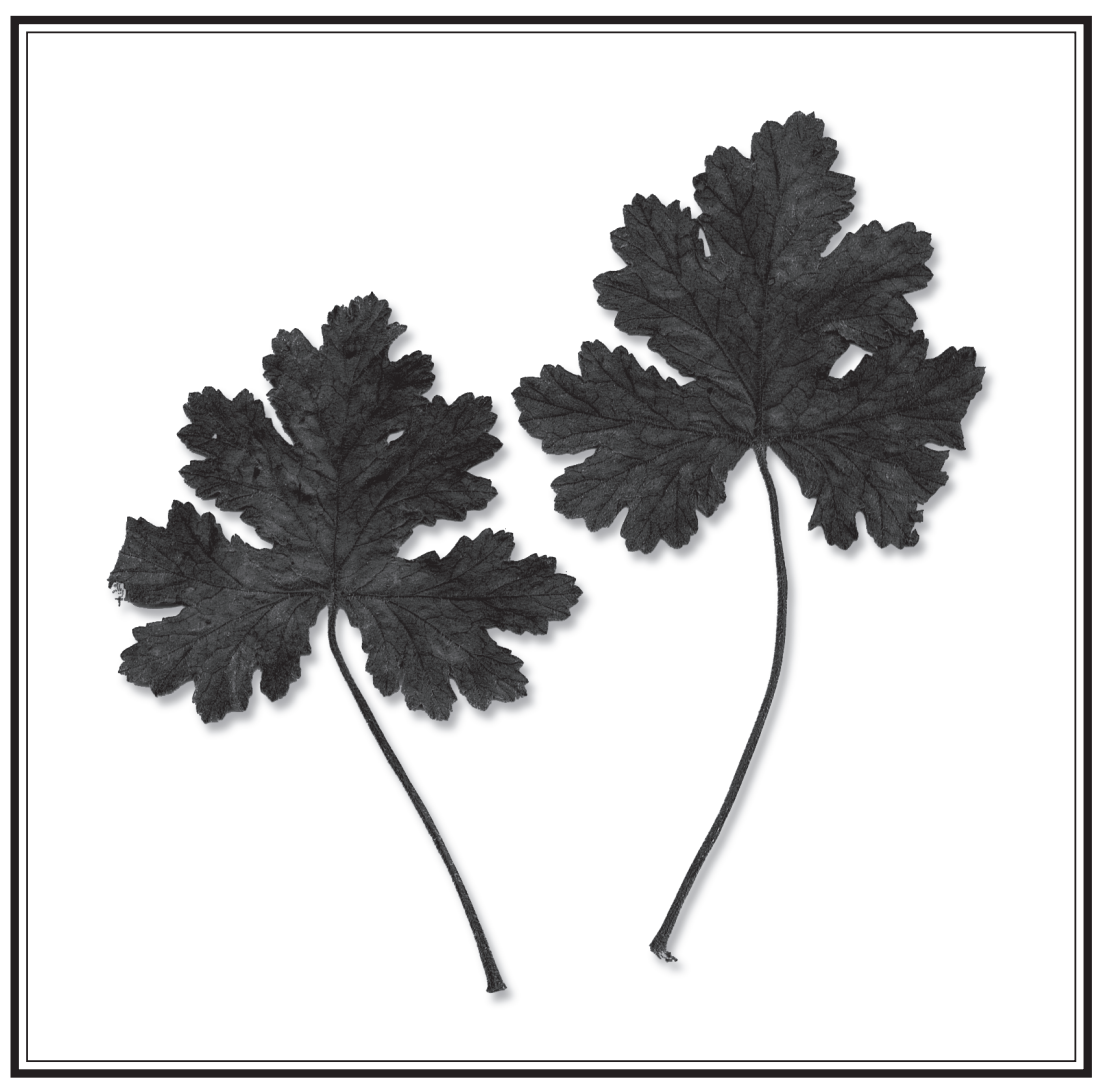

Primavera de 1988: Grene Moutinho visita a casa do poeta em

Itabira. Recolhe folhas no quintal, leva o presente para

Mindlin. Hoje repousam no miolo d'A Visita 